\title{
"Our brave sans-culotte". \\ La imagen de Mariano Luis de Urquijo según los escritos de Blanco White y lord Holland
}

\author{
Aleix Romero Peña \\ Universidad de La Rioja \\ aleix.romero@unirioja.es
}

Recibido: 12 de octubre de 2009

Aceptado: 16 de diciembre de 2010

\section{Resumen}

Las obras de José María Blanco White y lord Holland constituyen una fuente para estudiar y comprender el reinado de Carlos IV. En sus escritos hay unas breves referencias a Mariano Luis de Urquijo, un ministro de la monarquía cuyo perfil biográfico y político está todavía hoy por dilucidar. A través de las siguientes páginas intentaremos encuadrar los relatos de Blanco White y lord Holland en su contexto histórico y ofrecer, de paso, una perspectiva de cómo fue percibida la figura de Urquijo en Gran Bretaña.

Palabras clave: Mariano Luis de Urquijo, Carlos IV, Ilustración, jacobinismo, reforma, España, Gran Bretaña, José María Blanco White, lord Holland.

\section{'Our brave sans-culotte': Mariano Luis de Urquijo's image according to the writings of Blanco White and Lord Holland}

\begin{abstract}
The works of José María Blanco White and Lord Holland are a source to study and to understand the reign of the Spanish king Charles IV. In their writings there are some references to Mariano Luis de Urquijo, a Spanish minister which biographical and political profile is still unclear. In the following pages we try to classify the stories of Blanco White and Lord Holland in their historical context, providing a perspective of how Urquijo's figure was perceived in Britain.
\end{abstract}

Key words: Mariano Luis de Urquijo, Charles IV of Spain, Enlightenment, jacobinism, Spain, Britain, José María Blanco White, Lord Holland.

\section{Referencia normalizada}

Romero Peña F. (2011). "Our brave sans-culott”. La imagen de Mariano Luis de Urquijo según los escritos de Blanco White y lord Holland”. Cuadernos de Historia Moderna, Vol.36: pp. 109-128

Sumario: 1. Mariano Luis de Urquijo: ¿revolucionario o reformista? 2. Las fuentes de lord Holland y Blanco White 3. Un sans-culotte a la española 


\section{Mariano Luis de Urquijo: ¿revolucionario o reformista?}

Mariano Luis de Urquijo (1769-1817) es una figura que apenas cuenta con trabajos biográficos ${ }^{1}$ pero que posee un interés notable para comprender la España de finales del Antiguo Régimen. De familia vizcaína, Urquijo se decantó por la abogacía siguiendo la tradición familiar ${ }^{2}$, una decisión que a la postre iba a beneficiar su carrera profesional. Siendo estudiante en Salamanca se relacionó con algunos personajes ilustres - Ramón de Salas, Juan Meléndez Valdés, Diego Muñoz Torrero, etc.- y participó en las sesiones de la que con posterioridad se ha venido en llamar escuela iluminista salmantina, dedicada al fomento de la filosofía, el derecho y la economía política de acuerdo con las ideas ilustradas ${ }^{3}$. Tras concluir sus estudios el joven Urquijo quiso labrarse fama como hombre de letras, por lo que tradujo una tragedia de Voltaire y la acompañó de un erudito discurso sobre la necesidad de reformar el teatro español ${ }^{4}$. La postura defendida en el Discurso, que abogaba por la imitación del modelo teatral francés, irritó en el mundo del teatro, convulsionado por una encendida polémica sobre la renovación de las viejas formas teatrales barrocas mediante la adopción de las reglas neoclásicas ${ }^{5}$. Las compañías de teatro madrileñas dirigieron al ayuntamiento un escrito

${ }^{1}$ La única biografía que en la actualidad disponemos sobre Mariano Luis de Urquijo es SIERRA BUSTAMANTE, R.: Sinfonía bilbaína en tres tiempos, Bilbao, Caja de Ahorros Vizcaína, 1967, pp. 146-203. Se trata de un libro bien documentado pero que adolece de apriorismos y anacronismos propios de la época en que fue escrito, la posguerra. Otros estudios sobre el personaje en BADORREY, B.: Los orígenes del Ministerio de Asuntos Exteriores, Madrid, Ministerio de Asuntos Exteriores, 1999; FRANCO RUBIO, G. y LÓPEZ-CORDÓN, M. V.: "Un volterien espagnol a la fin du XVIIIe siècle: Mariano Luis de Urquijo", en Voltaire et ses combats. Actes du congrés internacional. OxfordParis, 1994, Oxford, Voltaire Foundation, 1997, pp. 1251-1262; SIERRA NAVA, L.: La reacción del episcopado español ante los decretos de matrimonios del ministro Urquijo, Bilbao, Estudios de Deusto, 1964 (especialmente las pp. 31-35); y OZANAM, D.: Les diplomates espagnols du XVIIe siècle, Madrid, Casa de Velásquez, 1998, (especialmente las pp. 453-454). Alfonso Carlos Saiz Valdivielso ha realizado un curioso ejercicio de ficción imaginando las conversaciones mantenidas por Urquijo y su amigo Jose de Mazarredo a lo largo de diferentes momentos de su vida en Mazarredo y Urquijo. Entre dos fuegos, Bilbao, Muelle de Uribitarte, 2008.

${ }^{2}$ Su padre, Francisco Policarpo de Urquijo, fue abogado de los Reales Consejos y ocupó diferentes cargos en el entramado funcionarial del Señorío de Vizcaya. En Madrid fue Alcalde de Casa y Corte. V. ARANBURUZABALA, Y.: "Grupos de parentesco en la carrera del honor: Los caballeros del Valle de Ayala en el siglo XVIII", en Nuevo Mundo. Mundos Nuevos, Coloquios, 2008. http://nuevomundo. revues.org/29732 La carrera de Francisco Policarpo progresó posteriormente a la sombra de la de su propio hijo.

${ }^{3}$ Véase BENEYTO, J.: La Escuela iluminista salmantina: discurso leído en la apertura del curso académico 1949-1950, Salamanca, Universidad de Salamanca, 1949, p. 15. Citado por RODRÍGUEZ, S.: Renacimiento universitario salmantino a finales del siglo XVIII. Ideología liberal del Dr. Ramón de Salas y Cortés, Salamanca, Ediciones Universidad de Salamanca, 1979, p. 148. Dicha escuela se relacionó también con otra de corte literario, la famosa escuela poética de Salamanca.

${ }^{4}$ La muerte de César. Tragedia francesa de Mr. de Voltaire, traducida en verso castellano y acompañada de un Discurso del traductor sobre el estado actual de nuestros teatros y necesidad de su reforma. Por Don Mariano Luis de Urquijo. Madrid. Blas Román, 1791. Su precio era de 10 reales en edición rústica y 12 en pasta. Gazeta de Madrid, no 83 de 18/11/1791, p. 764.

${ }^{5}$ Las ideas de Urquijo sobre el teatro están expuestas en BITTOUN-DEBRUYNE, N.: "Le théâtre français: un modèle pour Mariano Luis de Urquijo", en AYMES, Jean-René (ed.): L'image de la Fran- 
para que el libro de Urquijo fuese retirado de la circulación, a lo cual se las respondió que presentasen querella en los tribunales ${ }^{6}$. Juan Antonio Llorente escribe que fue interpuesta en el Santo Oficio una denuncia contra Urquijo por impiedad religiosa. Por el mismo testimonio se conoce que los inquisidores verificaron dicha acusación, pero que finalmente Urquijo se vio libre de una pena severa al ser nombrado oficial de la secretaría de Estado el 15 de agosto de $1792^{7}$.

Cuando pasó a formar parte de la plantilla de la secretaría de Estado, Urquijo ocupó el cargo de oficial noveno, que era el último puesto en el escalafón jerárquico. Seis años más tarde habría de alcanzar su cima en lo que fue un ascenso profesional meteórico, siempre dentro de la institución, lo que le reportó a Urquijo un codiciado bagaje en la carrera administrativa. Durante ese tiempo desempeñó además una misión diplomática en Londres, donde sirvió como secretario de la embajada, permaneciendo allí por unos pocos meses hasta que la guerra declarada entre España y Gran Bretaña le obligó a abandonar el país en noviembre de 1796. Aunque breve, aquel destino dio que hablar. En sus Memorias Godoy cuenta que envió a Urquijo a Londres como castigo por sus intrigas en la secretaría ${ }^{8}$. José Nicolás de Azara abunda en ello, relatando que se dio orden al embajador en la capital británica para que no se confiara a Urquijo ningún asunto ${ }^{9}$. No obstante, Urquijo replica que no sólo tuvo comisión diplomática, sino que recibió más de siete cartas reservadas de Godoy agradeciéndole sus servicios ${ }^{10}$. Lo que pudo hacer Urquijo durante aquel intervalo de tiempo en la capital británica también alimentó las plumas de lord Holland y Blanco White, como tendremos ocasión de comprobar.

El 13 de agosto de 1798 Urquijo, por entonces oficial mayor más antiguo, fue habilitado como secretario de Estado después de que el titular, Francisco de Saavedra, sufriese una extraña enfermedad. Dado el ambiente de especial conflictividad que reinaba en la secretaría hubo quien especuló con que la baja de Saavedra fue provocada por un veneno, barajándose entre diversas hipótesis con la posibilidad de

ce en Espagne pendant la seconde moitié du XVIII siècle, París y Alicante, Presses de la Sourbone Nouvelle, 1996, pp. 139-155.

${ }^{6}$ Véase LAMARQUE, M. P.: "Nota sobre Mariano Luis de Urquijo". Revista de la Biblioteca, Archivo y Museo, volumen VI, 1929, pp. 470-477.

${ }^{7}$ Cfr. LLORENTE, J.A.: Histoire critique de l'Inquisition en Espagne, París, Treuttel et Würtz, 1818, 2a edición, pp. 103-113. El testimonio de Llorente es cuestionado en CASO, J.M. "La Inquisición en la España borbónica, el declive del Santo Oficio (1700-1808): los hechos y la actividades inquisitoriales: Inquisición y Revolución Francesa: los procesos de Jovellanos y Urquijo", en J. PÉREZ VILLANUEVA: Historia de la Inquisición en España y América, Madrid, Biblioteca de Autores Cristianos, 2000, pp. 1317-1338. Caso aduce como argumento a sus hipótesis que aunque las obras de Voltaire figuraban en el Índice de libros prohibidos, la traducción de Urquijo no apareció hasta la edición del Índice de 1796.

${ }^{8}$ GODOY, M.: Memorias, edición de Emilio La Parra y Elisabel Larriba, Alicante, Publicaciones de la Universidad de Alicante, 2008

${ }^{9}$ Véase SÁNCHEZ ESPINOSA, G.: Memorias del ilustrado aragonés don José Nicolás de Azara, Zaragoza, Instituto Fernando el Católico, 2000, p. 319. Para evitar cualquier refutación Azara recalca que la orden "existe".

${ }^{10}$ Cfr. URQUIJO, M. L.de: Apuntes para la memoria sobre mi vida política, persecuciones y trabajos padecidos en ella, edición a cargo de Aleix Romero Peña, Logroño, Sin Índice, 2010, p. 85. 
que se lo hubiera suministrado el mismo Urquijo ${ }^{11}$. Saavedra, sin embargo, no se vio exonerado como secretario hasta finales de febrero de 1799, cuando era manifiesta ya su lenta recuperación ${ }^{12}$, demostrando así que el relevo de Urquijo fue una solución forzada por las circunstancias y que éste no participó en la supuesta intriga. Por su parte, nuestro personaje prosiguió con la política de iniciativa ilustrada seguida por sus predecesores, aunque acentuando aún más el ritmo de las reformas ${ }^{13}$. Esta aceleración terminó congestionando las estructuras de la monarquía, en vez de favorecer su dinamización y modernización, fomentando las críticas en torno a la acción de gobierno. Por ello una de las principales objeciones atribuibles al programa reformista de Urquijo es la de que no buscó concitar apoyos generales. Sabiéndose abrigado por el apoyo de una minoría ilustrada, Urquijo pretendió transformar las estructuras sociales sin tener en cuenta a la propia sociedad, siguiendo en ello los esquemas del despotismo ilustrado. Su gran error político, no obstante, fue la pérdida del favor real porque Carlos IV temió que las medidas impulsadas pusieran en peligro el precario equilibrio de poderes que sustentaba a la monarquía española.

La veta reformista se hizo evidente desde los comienzos de Urquijo en la secretaría. Ya en septiembre de 1798, apenas pasado un mes desde su nombramiento, salieron a la luz los cuatro decretos de desamortización de bienes de obras pías, con los que se pretendía contener la imparable crisis hacendística. No sólo no lograron dicho objetivo, sino que al año siguiente los vales se depreciaron y los precios subieron vertiginosamente, produciendo las protestas del pueblo, el clero y los comerciantes extranjeros ${ }^{14}$. Tal fue el fracaso que Urquijo endosó la responsabilidad del proyecto al secretario de Hacienda, el mallorquín Miguel Cayetano Soler, asegurando que "ni en la disposición en que se han hecho pudo adoptarlas jamás mi cabeza, ni remotamente pertenecieron a mi ministerio"15. Más polémico aún resultó el decreto de dispensas matrimoniales. Se trataba de una compleja disposición que conciliaba los aspectos ideológicos, pues representaba el regreso de una Iglesia primitiva, en la que los papas disfrutaran de menos privilegios ${ }^{16}$; económicos, al conllevar su aplicación el ahorro de miles de reales que se consumían anualmente en gastos para la negociación de dispensas en Roma ${ }^{17}$; y finalmente diplomáticos, porque el papa Pío VI había

\footnotetext{
${ }^{11}$ Véase SÁNCHEZ ESPINOSA, G.: op. cit. (nota 8), p. 320.

${ }^{12}$ Véase SAAVEDRA, F. de: Los decenios (autobiografía de un sevillano de la Ilustración), Sevi1la, Servicio de Publicaciones del Ayuntamiento de Sevilla, 1995, pp. 287-288 y 310-311.

${ }^{13}$ Véase LA PARRA, E.: La alianza de Godoy con los revolucionarios (España y Francia a fines del siglo XVIII), Madrid, CSIC, 1992, pp. 75-82. Véase también del mismo autor: "La crisis política de 1799", en Revista de historia moderna: Anales de la Universidad de Alicante, nº 8-9, 1988-90, pp. $219-232$

${ }^{14}$ Véase LA PARRA, E., art. cit. (nota 13, 1988-90), pp. 220-222. Sobre la desamortización véase HERR, Richard: La Hacienda Real y los cambios rurales en la España del Antiguo Régimen, Madrid, Instituto de Estudios Fiscales, 1991

${ }^{15}$ Véase URQUIJO, M. L. de: op. cit. (nota 9), p. 46.

${ }^{16}$ Véase EGIDO, T.: "La religiosidad de los ilustrados", en Historia de España, tomo XXXI, col. Menéndez Pidal, Madrid, Espasa-Calpe, 1987, pp. 408-410

${ }^{17}$ Véase OLAECHEA, R.: Las relaciones hispano-romanas en la segunda mitad del XVIII. La agencia de preces, Zaragoza, 1965, tomo II, p. 494. La cantidad total ascendió de los 196.526 escudos romanos en 1795 a los 376.820 escudos en 1797.
} 
muerto y se temía que en la elección del nuevo pontífice intervinieran potencias no católicas como Rusia o Gran Bretaña, lo que prolongaría inevitablemente el tiempo de decisión ${ }^{18}$.

A pesar de que aquellos eran unos momentos de especial debilidad para el catolicismo, la nueva ley no recibió grandes muestras de adhesión del episcopado español, salvo por parte de una minoría ilustrada ${ }^{19}$. Esta falta de entusiasmo se fundamenta en que el decreto implicaba la intromisión del poder real en las prerrogativas de la Iglesia. Los obispos y arzobispos temían convertirse en simples delegados del rey, que pasaba a ser quien decidía sus consagraciones. Vista la respuesta general, el secretario de Gracia y Justicia, que a la sazón era el ultramontano José Antonio Caballero, envió a los obispados una circular advirtiendo que no se tolerarían oposiciones de ningún tipo ${ }^{20}$. Urquijo, en lo que parece una huida hacia delante, amplió su ofensiva reformista al tribunal del Santo Oficio, reprendiéndole por entrometerse en la vida de los cónsules extranjeros ${ }^{21}$. Se ha dicho que el objetivo de Urquijo era la abolición de la Inquisición ${ }^{22}$, pero nunca llevó aquellas acometidas a algo tan profundo.

Urquijo planteó en las relaciones exteriores un difícil equilibrio entre la amistad con la república francesa y la neutralidad hacia el resto de potencias europeas, a excepción de Gran Bretaña ${ }^{23}$. En realidad no pudo evitar la creciente injerencia francesa en los asuntos internos españoles, que había dado inicio la firma del tratado de San Ildefonso en 1796, comprometiendo seriamente la imagen internacional de la monarquía. Este ascendiente se hizo perceptible tanto en los aspectos militares como diplomáticos, económicos y también ideológicos ${ }^{24}$. Las presiones del Directorio francés sobre Urquijo fueron constantes, revelando su grado de intensidad el extremo de que los Directores pretendieron que fuera sustituido por alguien más inclinado a sus miras ${ }^{25}$. La disposición española hacia su aliada quedó en entredicho al flaquear en dos asuntos de la máxima importancia: el estancamiento de la difícil negociación

${ }^{18}$ Véase SIERRA NAVA, L.: op. cit. (nota 1), pp. 42-43.

${ }^{19}$ Juan Antonio Llorente reunió en su Colección diplomática (Madrid, 1809) diecinueve respuestas - de sesenta posibles- que iban desde la adhesión entusiasta al frío acatamiento. Se sabe por el testimonio de embajadores extranjeros que otros obispos se opusieron tajantemente. V. OLAECHEA, R., op. cit. (nota 17), pp. 583-584.

${ }^{20}$ Cfr. LLORENTE, J. A.: Colección diplomática de varios papeles antiguos y modernos sobre dispensas matrimoniales y otros puntos de disciplina eclesiástica, Madrid, 1809, nº 15, p. 64.

${ }^{21}$ Véase LLORENTE, J. A.: op. cit. (nota 7), p. 109.

${ }^{22}$ Cfr. VILLANUEVA, J. L.: Vida literaria, Londres, Imprenta de A. Macintosh, 1825, Tomo I, p. 95.

${ }^{23}$ Cfr. FRANCO RUBIO, G. y LÓPEZ-CORDÓN, Ma. V.: op. cit. (nota 1), p. 1256.

${ }^{24}$ Algunos miembros de la Iglesia constitucional francesa escribieron a comienzos de 1799 un folleto significativamente titulado Observaciones sobre las Reservas de la Iglesia en España por los obispos reunidos en París, con el que pretendía alentar a la realización de reformas regalistas. V. LA PARRA, Emilio: "Iglesia y grupos políticos en el reinado de Carlos IV", en Hispania Nova, numero 2 (2001-2002) http://hispanianova.rediris.es/general/articulo/022/art022.htm

${ }^{25}$ El episodio se encuentra detallado en CORONA BARATECH, C.: Notas para el reinado de Carlos IV. La cuestión entre el ministro Urquijo y el embajador Guillemardet, Madrid, CSIC, 195 ?. Finalmente Carlos IV desatendió las presiones y nombró a Urquijo secretario de Estado interino el 21 de febrero de 1799 . 
de la paz con Portugal, en la que Carlos IV ejercía como mediador, y la imposibilidad de llevar a la práctica la proyectada colaboración naval hispano-francesa por desavenencias entre ambas potencias ${ }^{26}$. El Directorio llegó a difundir que el principal escollo para la alianza era el propio Urquijo, dando lugar a los rumores de que éste era un agente inglés o que mantenía contactos con el partido jacobino. Estas habladurías pasaron posteriormente a la corte española a través de quien fuera embajador en Francia, Azara ${ }^{27}$.

La tensión con Francia llegó a su grado más alto tras el golpe de Brumario. Urquijo desdeñó el nuevo régimen del consulado porque pensaba, teniendo en cuenta el historial de inestabilidad política de la Francia revolucionaria, que no duraría mucho tiempo ${ }^{28}$. Por su parte Napoleón, flamante Primer Cónsul, cuestionó la permanencia de Urquijo al frente del ministerio ${ }^{29}$. Con el tiempo los cálculos políticos limaron las asperezas y facilitaron el acuerdo. Napoleón pretendía valerse de los tres puntos estratégicos que, en su opinión, representaba la monarquía española: los intereses dinásticos de la familia Borbón en Italia, la capacidad marítima y las riquezas supuestamente infinitas que suministraban las colonias americanas ${ }^{30}$. Urquijo, en cambio, no tenía un planteamiento tan profundo; su preocupación esencial era rehabilitar su maltrecha imagen política asegurando el futuro del ducado de Parma.

Tras ser allanados los obstáculos venalidad mediante, el 1 de octubre de 1800 España y Francia firmaron el tratado de San Ildefonso, por el cual la primera cedía la extensa colonia de la Luisiana a cambio de la conversión de Parma en reino y el consiguiente engrandecimiento territorial ${ }^{31}$. El contenido del tratado habría de ser cuestionado más adelante. En sus Memorias Godoy criticó la desproporción de la permuta, declinando cualquier responsabilidad en la misma con el argumento de que la negociación se llevó en secreto ${ }^{32}$. Pero en realidad, a aquellas alturas Urquijo ya había empezado a ser marginado de las decisiones políticas, por lo que sus posibles objeciones a las cláusulas del acuerdo, en caso de producirse, apenas tuvieron trascendencia ${ }^{33}$. El príncipe de la Paz, que nunca perdió el contacto epistolar con Carlos y María Luisa, fue recuperando su confianza conforme avanzaba el gobierno

${ }^{26}$ Cfr. FUGIER, A.: Napoleón y España, 1799-1808, Madrid, Sociedad Estatal de Conmemoraciones Culturales, Madrid, 2008, p. 78.

${ }^{27}$ Así lo atestiguó en la carta que envió a Godoy informándole sobre la situación de las relaciones hispano-francesas. V. GIMENO PUYOL, M.D., Epistolario (1784-1804), Madrid, Castalia, 2010, pp. 786-795. Sobre esta misiva volveremos a tratar más adelante.

${ }^{28}$ Véase LA PARRA, E.: "Les changements politiques en Espagne après Brumaire", en Annales historiques de la Révolution française, $\mathrm{n}^{\circ} 318$ (octubre-diciembre de 1999): La France du 18 Brumaire et l'étranger, pp. 695-712.

${ }^{29}$ AHN, Estado, leg. 4047.2 Mazarredo a Urquijo, París, 30-XII-1799. Sobre el contexto de la conversación referida en la carta, la negociación de una expedición naval combinada entre las dos aliadas, véase CARLAN, José María: Navíos en secuestro. La escuadra española del Océano en Brest (17991802), Madrid, Instituto Histórico de Marina, 1951.

${ }^{30}$ Véase FUGIER, A.: op. cit. (nota 26), pp. 86-95.

${ }^{31}$ Ibidem, pp. 95-118.

${ }^{32}$ Cfr. GODOY, M.: op. cit. (nota 8), p. 727.

${ }^{33}$ Cfr. LEMA, marques de: "Antecedentes políticos y diplomáticos de los sucesos de 1808", en Nuestro Tiempo, Año IX, no 129, septiembre de 1909, pp. 294-295. 
de Urquijo y se ponían de manifiesto los numerosos obstáculos con que chocaba su política. La influencia recuperada por Godoy se hizo patente no sólo en el ánimo de los monarcas, a quienes visitaba con frecuencia en los sitios reales, sino también por su correspondencia con destacados generales o sus numerosos entrevistas con el secretario de Hacienda ${ }^{34}$.

El 29 de marzo de 1800 la elección de un nuevo papa dejó sin efecto la principal reforma del ministerio Urquijo, el decreto de dispensas matrimoniales. Los vanos intentos por parte del embajador español en Roma, Pedro Gómez Labrador, para que Pío VII validara la regalías consiguieron, como efecto no deseado, que el pontífice solicitara la remoción de Labrador ${ }^{35}$. Poco a poco fue estrechándose contra Urquijo una cábala compuesta por el nuncio apostólico, Godoy y el partido "beato", conformado por los elementos más reaccionarios de la corte. El golpe definitivo tuvo lugar cuando Carlos IV recibió una carta del papa en la que le aconsejaba que apartase de sus puestos a aquellos hombres:

que engreídos de una falsa ciencia pretendían hacer andar a la piadosa España los caminos de perdición donde nunca había entrado en los siglos de la Iglesia, y que cerrase sus oídos a los que, so color de defender las regalías de la corona, no aspiraban sino a excitar aquel espíritu de independencia que, empezando por resistir el blando yugo de la Iglesia, acababa después por hacer beberse todo freno de obediencia y sujeción a los gobiernos temporales, con detrimento y ruina de las almas en la vida presente y en los días eternos, quedando aparejado un gran juicio de estas cosas a aquéllos que presiden y gobiernan ${ }^{36}$

Tras su lectura el rey, siempre puntilloso en cuanto a los asuntos religiosos, se convenció no sólo de que Urquijo debía ser destituido, sino que también tenía que precaverse contra quienes apoyaron sus medidas religiosas, porque constituían un fermento de desórdenes públicos. El 10 de diciembre de 1800 se publicó la bula Auctorem fidei, que condenaba el jansenismo, junto con un decreto, a instancias del ministro Caballero, que ordenaba proceder contra quienes se opusieran a su contenido. Mientras varios supuestos jansenistas, partidarios de las reformas de Urquijo, comenzaban a ser perseguidos por la Inquisición, el secretario de Estado era destituido el 13 de diciembre, marchando al destierro a Vizcaya. En 1801 se le formó un proceso político que le llevó a la cárcel de Pamplona pero que, curiosamente, nada tuvo que ver con las medidas religiosas emprendidas, sino con las prácticas venales que tuvieron lugar durante las negociaciones del tratado de San Ildefonso.

Para concluir con la respuesta a la pregunta planteada en el epígrafe, Urquijo no fue un revolucionario sino un político reformista, aunque demasiado atropellado para el tempo que imprimía la situación española. Por eso sus proyectos de reforma terminaron en fiasco. Aunque la creación de cátedras de química y mineralogía,

\footnotetext{
${ }^{34}$ V. LA PARRA, E.: Manuel Godoy. La aventura del poder, Barcelona, Tusquets, 2002, pp. 221-232..

${ }^{35}$ SIERRA NAVA, L.: La caida del primer ministro Urquijo en 1800, Madrid, CSIC, 1963.

${ }^{36}$ Cfr. GODOY, M.: op. cit. (nota 8), p.735.
} 
la instauración de un gabinete de Historia natural, la introducción del telégrafo óptico o el patrocinio de la expedición de Humboldt por América sean aspectos muy sugerentes, sólo incumbieron entonces a una pequeña elite ilustrada. Otros aspectos interesantes, como la sabia combinación entre política exterior e Ilustración que supuso el tratado de paz firmado con la regencia de Marruecos en 1799 -en el que, al margen de los ventajosos acuerdos comerciales, se abolía la esclavitud entre ambas naciones- apenas tuvieron la relevancia merecida. La imagen general de la etapa está marcada por la crisis hacendística, el enfrentamiento político y el miedo a que en España prendiese la mecha de la revolución. Pese a todo ello, no se le puede negar al gobierno de Urquijo el mérito de haber sido el más ilustrado del siglo XVIII español, por el alcance de sus medidas y reformas ${ }^{37}$.

\section{Las fuentes de lord Holland y Blanco White}

Henry Richard Vassal Fox, más conocido por el título aristocrático de lord Holland, fue un eminente político y hombre de letras, pero también, desde que contaba no más de veinte años, un incansable viajero que recorrió el continente europeo en los convulsos de tiempos de finales del siglo XVIII y comienzos del XIX. De todos los sitios por donde pasó, guardó siempre un especial cariño hacia España, hasta el punto de que en Gran Bretaña fue motejado de españolado. Tanto él como su mujer, lady Holland ${ }^{38}$, se empaparon de la política, la historia, la literatura y las costumbres españolas, trazando unos vínculos de amistad con prominentes personajes que perduraron más allá de las diferentes vicisitudes vitales de unos y otros. Seguramente coadyuvó en esa labor el ideario liberal del lord inglés, que se convirtió en todo un referente durante las cortes de Cádiz. Holland, destacado miembro del partido whig, entendía a la Constitución como un fiel reflejo de la realidad histórica y social de la nación que se dotaba de ella. Esa noción, incompatible con la introducción de leyes extrañas e incompatibles con las costumbres y hábitos nacionales, implicaba la defensa de un texto constituyente moderado. Tal planteamiento sedujo a un grupo de diputados gaditanos conocidos "realistas ilustrados", que defendieron en las cortes un modelo que garantizase un mayor equilibrio entre las cámaras y el rey frente a los que se inclinaban por la vía francesa, más democrática y representativa ${ }^{39}$. Holland se trasladó junto con su mujer a Sevilla, sede de la Junta Suprema, para defender sus tesis, entrando en contacto con viejos amigos de sus anteriores viajes y conociendo a otros nuevos ${ }^{40}$.

${ }^{37}$ Véase LA PARRA, E.: op. cit. (nota 13), p. 166.

${ }^{38}$ Sobre este personaje, fascinante aunque poco conocido, véase CALVO MATURANA, Antonio Juan: "Elizabeth Holland: portavoz de los silenciados y cómplice de un tópico", en Cuadernos de Historia Moderna, no 29, 2004, pp. 65-90.

${ }^{39}$ Cfr. FERNÁNDEZ SARASOLA, I. "Los partidos políticos en el pensamiento español (17831855), en Historia constitucional, $\mathrm{n}^{\circ}$ 1, 2000, p. 108. Sobre el fracaso del modelo constitucional inglés en las Cortes de Cádiz véase VARELA SUANZES, J.: "Los modelos constitucionales en las Cortes de Cádiz", consultable en http://www.cervantesvirtual.com/servlet/SirveObras/12476283212303841654679/ p0000001.htm

${ }^{40}$ Véase MORENO ALONSO, M.: La forja del liberalismo en España. Los amigos españoles de Lord Holland (1793-1840), Madrid, Congreso de los Diputados, 1997, pp. 29-46. 
Entre éstos último figuraba José María Blanco White. Su encuentro dio origen a una amistad que es el punto de partida de este capítulo.

Blanco White es un personaje singular, de aquéllos que pueblan los márgenes de la historia española contemporánea. Español desarraigado, pasó los treinta últimos años de su vida en Londres y murió en el seno de la Iglesia unitarista, lo cual resume perfectamente el nivel de su integración en la vida inglesa. Blanco fue un periodista y escritor que se hizo famoso por sus reflexiones sobre la política, la historia, la literatura o la religión, haciendo de puente entre mundos -el español y el inglés, aunque tampoco olvidar el americano- entonces contrapuestos. De su rica trayectoria ${ }^{41}$ sólo resaltaremos los puntos que interesan al trabajo.

Blanco White estuvo relacionado en España con el Instituto Pestalozziano de Madrid, un innovador centro de educación elemental fundado por el príncipe de la Paz. Godoy reparó en sus cualidades y le propuso ser el receptor del infante Francisco de Paula. El hecho de que finalmente no recibiera dicho empleo habría de determinar el resto de su vida. Por de pronto se vio obligado a ocultar su vinculación godoísta tras del triunfo del motín de Aranjuez ${ }^{42}$. Posteriormente, al igual que el resto de los españoles, la fulgurante concatenación de los acontecimientos que culminaron en la proclamación de una nueva dinastía colocó a Blanco ante un dilema excepcional. Las dudas se le disiparon con la vigorosa reacción popular, que tuvo ocasión de constatar en los acontecimientos del 2 de mayo, por lo que regresó a su Sevilla natal, que se había alzado contra los franceses. En la capital hispalense, junto a su amigo Quintana, protagonizó la segunda fase de la conocida publicación Seminario patriótico que devino, según Martin Murphy, en el primer periódico de opinión política libre -o "cuasi libre"- publicado en España ${ }^{43}$.

En este momento, exaltado por el brío de la insurrección popular, se decantó por unas Cortes representativas, soberanas y unicamerales. Su inspiración en el modelo revolucionario francés es evidente. Fue entonces cuando lord Holland se fijó en él. El aristócrata inglés vio en el brillante y ardoroso periodista al mensajero más idóneo de sus planteamientos políticos, siempre que Blanco atemperara su fervor jacobino ${ }^{44}$. Sin embargo los Holland regresaron a Gran Bretaña en 1809 mientras Blanco continuó publicando en Sevilla sus encendidos artículos, a pesar de las presiones, hasta que un año más tarde las tropas francesas entraron en la ciudad. La ocupación despertó diferentes reacciones. La Junta, dispuesta a resistir a toda costa, se trasladó a Cádiz.

${ }^{41}$ La figura Blanco White, antaño uno de los grandes españoles olvidados, está conociendo hoy en día un auténtico revival. Proponer una bibliografía esencial sobre el personaje, habida cuenta de la producción que existe sobre el mismo, rebasa las pretensiones de este trabajo. Por eso proponemos tres títulos interesantes: DURÁN LÓPEZ, F.: José María Blanco White o la conciencia errante, Madrid, Fundación José Manuel Lara, 2005; MORENO ALONSO, M.: Blanco White. La obsesión de España, Alfar, Sevilla, 1998; MURPHY, M., Blanco White. Self-banished Spaniard, New Haven y Londres, Yale University Press, 1989.

${ }^{42}$ Cfr. GARNICA, A.: Autobiografía de Blanco White, Sevilla, Servicio de Publicaciones de la Universidad de Sevilla, 1988, 2ª edición, p. 181. Véase además DURÁN LÓPEZ, F.: op. cit. (nota 41), pp. 112-113.

${ }^{43}$ Cfr. MURPHY, M.: op. cit. (nota 41), p. 53.

${ }^{44}$ Véase MURPHY, M.: op. cit. (nota 41), p. 53. 
Otros, como Alberto Lista, Manuel María de Arjona o Félix Reinoso, antiguos condiscípulos de Blanco, se pasaron a las filas afrancesadas. Frente a esas dos posturas Blanco optó por abandonar España embarcándose a Londres. No regresaría.

Refugiado en la capital británica, Blanco sacó, a través del Foreign Office, un periódico en su lengua materna, llamado El Español. Paulatinamente sus artículos pasaron a mostrar una línea más acorde con los intereses británicos frente a los de la etapa anterior, lo que le llevó a chocar con los amigos que quedaron en España, como Quintana. Blanco White no era un periodista mercenario, por lo que las opiniones que muestra obedecen a un profundo cambio en sus convicciones ${ }^{45}$. Blanco volvió a coincidir con los Holland, haciéndose preceptor de uno de sus hijos. Esta relación no estuvo a salvo de las estridencias pues Blanco fue adoptando posturas más conservadoras tras la lectura de Edmund Burke ${ }^{46}$. A pesar de ello se vio también influido por las posturas del aristócrata inglés, como lo demuestras las Letters from Spain que fueron apareciendo en la prensa inglesa en 1821.

En dicha obra Blanco, pretextando ofrecer la biografía de un clérigo español, presenta todo un cuadro sobre el estado moral de la España de Carlos IV. La huella de los Holland, que tan bien conocían el país y el reinado, se encuentra por todas partes. Su gestación se debió a la perspicaz instigación de lady Holland. Este apoyo le permitió a Blanco documentarse en los fondos sobre España que se hallaban en la biblioteca de la Holland House, así como los diarios y notas de los Holland ${ }^{47}$. Nada tiene de extraño por tanto que tantos las Letters from Spain como el diario de Holland, que sería publicado bajo el nombre de Foreign reminiscences, presenten abundantes similitudes, ya que compartían las mismas fuentes de información. Aunque los Holland nunca conocieron a Urquijo, su segunda estancia en España, que se prolongó de 1802 a 1805, se encuentra muy próxima cronológicamente a la caída de Urquijo. Seguramente tuvieron que escuchar de boca de sus anfitriones españoles detalles sobre esta desgracia política. Pero si sus noticias se hubiesen construido tan sólo a partir de rumores, los relatos no pasarían de ser un anecdotario cortesano basado en testimonios orales e indirectos.

Entre los fondos de lord Holland figura una carta escrita por José Nicolás de Azara en Barcelona y fechada a 26 de noviembre de $1799^{48}$, a la que lady Holland también se refiere ${ }^{49}$. Azara había sido embajador en Francia hasta el 14 de agosto de 1799, cuando fue cesado. Para entender el sentido de su epístola, destinada a Godoy, hay que detenerse primero en la pequeña historia de sus desencuentros con Urquijo. $\mathrm{Su}$ origen se encuentra en la desquiciante mediación para la paz entre Francia y Portugal. La monarquía española quería evitar a toda costa una guerra contra una

\footnotetext{
${ }^{45}$ Véase DURÁN LÓPEZ, F., op. cit. (nota 41), pp. 151-164.

${ }^{46}$ Político y filósofo inglés, perteneció al partido whig hasta que las disensiones en torno a la Revolución Francesa dentro de la formación -que él mismo atizó con la publicación de sus Reflexiones sobre la Revolución Francesa (1790)- le llevaron a romper con ella. En la actualidad se le considera padre del conservadurismo y uno de los fundadores del liberalismo clásico.

${ }^{47}$ Véase MORENO ALONSO, M.: op. cit. (nota 41), pp. 136-137.

${ }^{48}$ Ibidem, p. 83. La carta se conserva en BM. Add. 51623 (20-23). Barcelona, 26 noviembre 1799

${ }^{49}$ Véase Lady HOLLAND: Spanish Journal, Londres, Longsman, Green \& co., 1910, p. 159.
} 
familia reinante emparentada con ella, que además conllevaría inevitablemente el paso de tropas francesas por el país, pero las condiciones que imponían cada una retrasaba el acuerdo. La abrupta salida de la capital francesa de un enviado portugués, que pretendía negociar por su cuenta, abrió la caja de los truenos. Azara fue acusado por la corte lusa de estar vendido a los franceses y de no ser un negociador válido. Informado por el gobierno francés de las imputaciones, Azara pensó que Urquijo le había descubierto al pasar copia a Lisboa de los oficios que enviaba a Madrid, cuando en realidad lo que pretendía el ministro era aclarar con la corte portuguesa la actuación de sus emisarios ${ }^{50}$.

La relación entre ministro y embajador, lejos de mejorar, fue empeorando conforme pasaba el tiempo. Tras haber sido propuesto imprudentemente por parte del embajador francés el nombre de Azara como candidato preferido por el Directorio para el puesto de secretario de Estado, la correspondencia de Urquijo quedó limitada a "mentiras, falsedades, engaños y hipocresías ambiciosas y cortesanas" 51 . Así lo entendió Azara. Por su parte Urquijo no se quedó atrás. Hablando sobre sus negociaciones acerca de la unión de las escuadras francesa y española, el secretario de Estado le espetó: que "jugamos a la Gallina ciega con los Navíos, y que Vm. es el palo que da, sin saber cómo, pues se sirven de su Persona para pedir y sin explicar varían" ${ }^{52}$. El enfrentamiento había alcanzado tal extremo que el embajador español confiaba más en las confidencias del gobierno francés que en las órdenes del secretario de Estado. Finalmente Azara salió de la embajada cuando Urquijo descubrió su participación en asuntos franceses de índole exclusivamente interna ${ }^{53}$.

La remoción irritó a Azara, que sintió ese final como un agravio personal a sus más de treinta años de servicio en la carrera diplomática ${ }^{54}$. Como venganza ante esa ignominia dirigió una apología al príncipe de la Paz, que era de los pocos que tenía contacto directo con los reyes, nada más cruzar la frontera con España. Conviene recordar al respecto que en sus Memorias, escritas durante el gobierno de Urquijo, Azara dijo sobre Godoy que poseía "la llave del corazón de la Reina, y que en queriendo sacrificar un poco sus inclinaciones, desbancará treinta Urquijos y treinta otros rivales en política y amor" 55 . Las anteriores palabras demuestran, por tanto, la encarnizada oposición contra la que ya presentaba el príncipe de la Paz a finales de 1799.

${ }^{50}$ CORONA BARATECH, C.: Notas para el reinado de Carlos IV. La fracasada mediación de España para la paz de Portugal con Francia", Universidad. Revista de Cultura y Vida Universitaria, ${ }^{\circ}$ 3, Zaragoza, 1946, pp. 83-132.

${ }^{51}$ Cfr. SÁNCHEZ ESPINOSA, G.: op. cit. (nota 9), p. 328.

${ }^{52}$ AHN, Estado, leg. 3999, confidencial de Urquijo a Azara, 10-V-1799

${ }^{53}$ Azara promovió el cierre del club jacobino del Manège y participó en la fracasada conspiración de Sieyès y Joubert para sustituir el Directorio por una república moderada o monarquía constitucional. Véase SÁNCHEZ ESPINOSA, G.: op. cit. (nota 9), p. 387 y ss.

${ }^{54}$ En la última carta dirigida a Urquijo, Azara le reprocha los modos de darle la dimisión, que dan la "apariencia y aparato de una desgracia completa y un destierro". AHN, Estado, leg. 4022, París, 14 de septiembre de 1799. Reproducida en GIMENO PUYOL, Mª. D.: op. cit. (nota 28), pp. 770-773.

${ }^{55}$ Cfr. SÁNCHEZ ESPINOSA, G.: op. cit. (nota 9), p. 348. 
En la carta Azara denunciaba el estado de la alianza, cuyo marasmo atribuía al ambicioso e inhábil Urquijo, rodeado y asesorado de personajes jacobinos como el cónsul general José de Lugo, los hermanos Gimbernat, el general O'Farrill y su esposa Teresa de Carasa o el embajador bátavo Valckenaar ${ }^{56}$. De esta forma Urquijo era asociado al partido jacobino. Esta explosiva epístola fue copiada y difundida por la corte. El oficial de la secretaría de Estado José García de León y Pizarro, que llegó a leerla, dijo que la misma que "era capaz, por su objeto, por su contenido y por su material redacción desaliñada y ridícula, de desacreditar al suscriptor de la Vida de Cicerón, donde hubiese algo de honor y sombra de Ilustración"s7. Urquijo también conoció la divulgación de su contenido e interrogó a Godoy al respecto, pero éste negó haber difundido las copias ${ }^{58}$.

Sería una de estas reproducciones la que pasó a manos de lord Holland, aunque desconozcamos por qué conducto. Se sabe, no obstante, que lord Holland y Azara fueron amigos. Precisamente cuando se reencontraron en 1802, tras retornar Azara a la embajada en Francia, le reprochó con sorna al inglés que su primer ministro Pitt le hubiese obligado a él, todo un caballero condecorado con distinciones borbónicas y papales, a ser un jacobino francés ${ }^{59}$. Aquel fríbolo juego de palabras, en el que Azara relacionaba "jacobino" con su lealtad a la alianza hacia la república francesa, revela que el concepto tenía un sentido político difuso para el diplomático español. ¿Le ocurriría lo mismo al redactar la resentida carta a Godoy?

\section{Un sans-culotte a la española}

José María Blanco White escribió las siguientes líneas sobre Urquijo:

The First Clerk of the Secretary of State's Office - a place answering to that of your under-secretary of State- was a handsome young man, called Urquijo. His name is probably not unknown to you, as he has a few years ago with the Spanish Ambassador in London, where his attachment to the French jacobins and their measures could not fail to attract some notice, from the unequivocal and heroical proof of self-devotion which he shewed to that party. It was, in fact, an attempt to drown himself in the pond at Kensington Gardens, upon learning the peace made by Buonaparte with the Pope at Tolentino ${ }^{60}$; a treaty which disappointed his hopes of seeing the final destruction of the Papal See, and Rome itself a heap of ruins, in conformity to a decree of the French

${ }^{56}$ Véase nota 27.

${ }^{57}$ Cfr. GARCÍA de LEÓN y PIZARRO, J.: Memorias, edición de Álvaro Alonso-Castrillo, Madrid, Centro de Estudios Políticos y Constitucionales, 1998, pp. 95-96

${ }^{58}$ Cfr. URQUIJO, M. L.: op. cit. (nota 10), p. 92. "Él me negó”, señala Urquijo, "que le hubiese sido dirigida dicha Carta por Azara, añadiendo que la había visto y era muy grosera”.

${ }^{59}$ Cfr. lord HOLLAND: Foreign reminiscences, by Henry Richard Lord Holland. Edited by his son, Henry Edward lord Holland, Londres Harper \& Brothers Publishers, 1850, p. 142

${ }^{60}$ El tratado de Tolentino, fue firmado en 1797 por Napoléon Bonaparte, entonces al mando de los ejércitos franceses en Italia, y Pío VI. Por sus condiciones el papa quedaba obligado a realizar grandes concesiones económicas y territoriales. Poco después, sin embargo, las tropas francesas entraron en Roma y expulsaron a Pío VI, que marchó camino del exilio. 
Directory. Fortune, however, having determined to transform our brave Sans-Culotte into a courtier, afforded at timely rescue from the muddy deep; and when, under the care of Doctor $V$-, he had been brought to understand how little his drowning would influence the events of the French war, he returned to Madrid, to wield his pen in the office where his previous qualification of "Joven de Lenguas" had entitled him to a place, till the rose, by seniority, to that of Under-Secretary.

Every Spanish minister has a day appointed in the course of the week-called Dia de Despacho- when he lays before the King the contents of his portfolio, to dispose of them according to his Majesty's pleasure. The Queen, who is excessively fond of power, never fails to attend on these occasions. The minister, during this audience, stands, or, if desired, sits on small stool near a large table placed between him and the King and Queen. The love of patronage, not of a business, is, of course, the object of the Queen's assiduity; while nothing but the love of gossip enables her husband to endure the drudgery of these sittings. During Saavedra's ministry, his Majesty was highly delighted with the premier's powers of conversation, and his inexhaustible fund of good stories. The portfolio was laid upon the table; the Queen mentioned the name of her protégés, and the King, referring all other business to the decision of the minister, began a comfortable chat, which lasted till bed-time. When Saavedra was taken with that sudden and dangerous illness which Godoy's enemies were inclined to attribute to poison (a suspicion, however, which both the favourite's character, and his subsequent lenity towards Saavedra, absolutely contradict) the duty of carrying the portfolio to the King devolved upon the Under-secretary. Urquijo's handsome person and elegant manners made a deep impression upon the Queen; and ten thousand whispers spread the important news, the next morning, that her Majesty had desired the young clerk to take a seat.

This favourable impression, it is more than probable, was heightened by a fresh pique against Godoy [...]. She [la Reina] now conceived the plan of making Urquijo, not only her instrument of revenge, but, it is generally believed, a substitute for the incorrigible favourite. But in this amours Court even a Queen can hardly find a vacant heart; and Urquijo's was too deeply engaged to one of Godoy's sisters ${ }^{61}$ to appear sensible of her Majesty's condescension. He mustered, however, a sufficient portion of gallantry to support the Queen in her resolution of separating Godoy from the Court, and depriving him of all influence in matters of government [...]

The two ministres, Saavedra and Jovellanos, had been rusticated to their native provinces; the first, on account of ill health; the second, from he Queen's unconquerable dislike. Urquijo, who seem to have been unable either to gain the King's esteem, or fully to return the Queen's affection, could keep his post no longer than while the latter's ever ready fodness for Godoy was not awakened by the presence of its object. The absence of the favourite, it is generally believed, might have been prolonged by good policy, and management of the King on the part of Urquijo, if his

${ }^{61}$ Se trata de María Antonia Godoy, marquesa de Branciforte, camarista de la reina y hermana del príncipe de la Paz. Véase MOLAS RIBALTA, P.: "Las primeras damas de la Orden de María Luisa", en Trocadero, 2000-2001, p. 273. Al comentar su relación de amantes, lady Holland refiere la historia de que la marquesa avisó a Urquijo del peligro que corría si permitía que su hermano regresara a la corte, pero que éste no le dio importancia. Cfr. lady HOLLAND, op. cit. (nota 52), pp. 152-153. 
rashness and conceit of himself had ever allowed him to suspect that any influence whatever was equal to that of his talents and person. Instead of strongly opposition a memorial of the Prince of the Peace, asking permission to kiss their majesties' hands upon the birth of a daughter borne, to him by the Princess his wife, Urquijo imagined the Queen so firmly attached to himself, that he conceived no danger from this transient visit of his offended rival. Godoy made his appearance at Court; and from that moment Urquijo's ruin became inevitable. His hatred of the Court of Rome had induced the latter to encourage the translation of a Portuguese work, against the extortions of the Italian Dataria ${ }^{62}$, in case of dispensations for marriage within the prohibited degrees. Thinking the public mind sufficiently prepared by that work, he published a royal mandate to the Spanish bishops urging them to resume their ancient rights of dispensations. This step had armed against its author the greater part of the clergy; and the Prince of Peace found it easy to alarm the King's conscience by means the Pope's nuncio, Cardinal Casoni, who made him believe that his minister had betrayed him into a measure which trespassed upon the rights of the Roman Pontiff. I believe that Godoy's growing dislike of the Inquisition spared Urquijo the horrors of dungeon within its precincts. He had not, however, sufficient generosity to content himself with the banishment of his enemy to Guipuzcoa. An order for his imprisonment in a fortress followed him thither in a short time - a circumstance, however, which might raise a suspicion that Urquijo had employed his personal liberty to make a second attempt against the recalled favourite ${ }^{63}$.

${ }^{62}$ Se refiere a la Tentación teológica, escrita por Antonio Pereira de Figuereido, que fue consejero del ministro Pombal, y publicada originalmente en Lisboa en 1766. De contenido regalista, Urquijo promovió su impresión junto con El espiritu de la jurisdicción eclesiástica, del napolitano Jenaro Cestani, pero el Consejo de Castilla dilató dictaminó en contra de su publicación por proponer ambas la disminución de la autoridad pontifica. AHN, Estado, leg. 3014, exp. "Cáseda y Muro (D. Francisco de)".

63 "El Primer Oficial de la Secretaría de Estado - un cargo que corresponde a vuestro vicesecretario de Estado- era un apuesto joven llamado Urquijo. Probablemente su nombre no te es desconocido porque él estuvo hace unos pocos años con el Embajador Español en Londres, donde su apego a los franceses jacobinos y sus medidas no pudieron causar ninguna sensación, más allá de la heroica e inequívoca prueba de devoción que él demostró hacia ese partido. Así, intentó ahogarse en puente de Kensington Gardens después de enterarse que Bonaparte había firmado la paz con el Papa en Tolentino; un tratado que frustró sus esperanzas de ver la destrucción final de la Santa Sede y a Roma misma hecha un montón de ruinas, según lo anunciaba un decreto del Directorio francés. La fortuna, sin embargo, determinó convertir a nuestro audaz sans-culotte en un cortesano, proporcionándole a tiempo un rescate del fondo fangoso; y cuando, bajo el cuidado del Doctor V, empezó a comprender lo poco que su ahogamiento influiría en las decisiones de la guerra francesa, regresó a Madrid a empuñar la pluma en la oficina donde su título anterior de Joven de Lenguas le dio derecho a tomar plaza, hasta que alcanzó, por antigüedad, esa Vicesecretaría. Cada ministro español tiene señalado un día en el transcurso de la semana -denominado Día de Despacho- en el que coloca ante el Rey los negocios que lleva en su cartera para solucionarlos de acuerdo con la voluntad de Sus Majestades. La Reina, que tiene un cariño excesivo al poder, nunca deja de estar presente en estas ocasiones. Durante esta audiencia el ministro permanece de pie o, si lo desean, se sienta en un pequeño escabel cerca de una larga mesa colocada entre él y el Rey y la Reina. El amor al mecenazgo, no a los asuntos políticos, es la razón de la asiduidad de la Reina, mientras la afición a los cotilleos permite a su marido soportar la dureza de estas sesiones. La cartera se dejaba sobre la mesa, la Reina mencionaba el nombre de sus protégés y el Rey, remitiendo el resto de los negocios al juicio del ministro, daba comienzo a una amable conversación que se prolongaba hasta la hora de acostarse. Cuando Saavedra fue atacado por aquella enfermedad repentina y peligrosa, que los enemigos de Godoy se inclinaron en atribuir a un veneno (una sospecha, sin embargo, completamente contradictoria con el carácter del favorito y su consiguiente 


\title{
Lord Holland, por su parte, narró el gobierno de Urquijo de la siguiente manera:
}

\begin{abstract}
In the meanwhile the Queen was more capricious and licentious in her conduct. Urquijo who, on the rupture with England in 1796, had returned from that country and become, in virtue of his rank in the public office, chief clerk, acted as secretary during the illness of his principal, Don Francisco Saavedra. That minister continued ill for some time, and it was necessary that some one conversant with the routine of office should, according to usage, re the dispatches to their Majesties. To give Urquijo the requisite rank for such an honour, he nominally appointed ambassador to the Batavian Republick ${ }^{64}$, and attended standing before a table at which the King and Queen were seated to read the official correspondence. Urquijo was young, hadsome and well made. Her Majesty was more stuck by the reader than edified by the dispatches. In defiance of etiquette, if not of propietry, she bade him take a
\end{abstract}

indulgencia hacia Saavedra), el deber de llevar la cartera al Rey correspondió al Vicesecretario. La belleza de Urquijo y sus elegantes ademanes causaron honda impresión en la Reina; y diez mil rumores esparcen la importante noticia de que Su Majestad desearía que la siguiente mañana el joven oficial tomara asiento. Es más que probable que esta impresión favorable fue intensificada por un vivo resentimiento contra Godoy [...] La Reina concibió en estos momentos el plan de convertir a Urquijo no sólo en instrumento de su venganza sino también, como se pensó, en sustituto de su incorregible favorito. Pero incluso en estos amores cortesanos a una Reina le puede costar encontrar un corazón desocupado; y Urquijo estaba bastante entretenido con una de las hermanas de Godoy como para aparecer receptivo a la condescendencia de la reina. Debió de conservar, sin embargo, la galantería suficiente para respaldar a la Reina en su resolución de separar a Godoy de la Corte y privarle de cualquier influencia en los asuntos de gobierno. Los dos ministros, Saavedra y Jovellanos, habían sido transferidos a sus provincias natales; el primero, a causa de su enfermedad; el segundo, como consecuencia de la insuperable aversión de la Reina. Urquijo, que parece haber sido incapaz de ganar la estimación del Rey o de responder satisfactoriamente a los sentimientos de la Reina, sólo podría conservar su puesto mientras el constante cariño demostrado hacia Godoy no fuese despertado de nuevo por la presencia de aquél. Se cree que la ausencia del favorito pudo haber sido prolongada a través de una política eficaz y del dominio conseguido por Urquijo sobre la voluntad del Rey, si la temeridad y la presunción le permitieron sospechar alguna vez de cualquier otra influencia semejante a la suya en talentos y persona. En vez de oponerse firmemente al recuerdo del Príncipe de la Paz después de que éste le pidiera permiso a través de la Princesa, su esposa, para besar las manos de Sus Majestades con motivo del nacimiento de su hija, tanto imaginaba Urquijo que era la atracción que provocaba en la Reina que no vio ningún peligro en la eventual visita de su ofendido rival. Godoy se presentó en la Corte; y desde ese momento la ruina de Urquijo fue ya inevitable. Su odio hacia la Santa Sede había inducido a éste último el valor de traducir una obra portuguesa contra las exhortaciones de la Dataría romana sobre dispensas para casarse dentro de los grados prohibidos. Creyendo que la mentalidad pública se encontraba suficientemente preparada con ese libro, publicó un decreto real urgiendo a los obispos que retomaran sus antiguos privilegios sobre dispensación. Este paso concitó contra su autor la oposición de la mayor parte del clero; y el Príncipe de la Paz logró alarmar fácilmente la conciencia del Rey mediante el nuncio del Papa, Cardenal Casoni, quien le hizo creer que su ministro le había traicionado con una medida que violaba los derechos del Pontífice Romano. Pienso que el creciente disgusto de Godoy con la Inquisición libró a Urquijo de los horrores de una mazmorra con sus precintos. No tuvo sin embargo la suficiente generosidad como para contentarse con el destierro de su enemigo a Guipúzcoa. Le siguió allí al poco tiempo una orden para su reclusión en una fortaleza - una circunstancia que, no obstante, puede llevar a la sospecha de que Urquijo se valió de su libertad personal para acometer una segunda tentativa contra el favorito ya mencionado". Cfr. DOBLADO, Leucadio (pseudónimo): Letters from Spain, Londres, Henry Colbun y cía., 1822, pp. 348-355.

${ }^{64}$ El 21 de octubre de 1798. 
chair and read the papers at his ease. Such condescension was the forerunner of greater favours. He was soon Minister of Foreign Affairs. Saavedra and Jovellanos were removed and banished; but as the removal of both, especially of Saavedra, was preceded of illness, many who hated the Prince of the Peace, ascribed their maladies to poison, administered, according to the version of former, with a view of facilitating the promotion of Urquijo, and, according to the equally improbable, surmises of the latter, to revenge the ingratitude and elude the enmity of those two ministers towards the discarded favourite.

The administration of Urquijo, with whom I was never personally acquainted, lasted longer than according to the strange stories reported of him could have appeared probable to any reasonable man. He was ignorant, rash, and presumptuous in the extreme. Averse to every institution of the country and every opinion of the people he was called upon to govern, he determined, nevertheless, to slight the individuals as well as to overlook the precautions most necessary to the execution of his arduous undertakings. So fanatically hostile was he to the Church of Rome, that when being chargé d'affaires in London, he first heard that General Buonaparte, by the peace of Tolentino, and at the intervention of the Spanish ambassador Azara, had spared the Papal government, he ran like a maniac from his house for more than a mil on the Uxbridge road, and threw himself in despair into a pond. Mr. Carlisle (note: This is a strange, almost an incredible story, but I give my authority. I made Mr. Carlisle repeat it to me above once, and he mentioned many circumstances attending the event, and assured me that he had maintened an intimacy and correspondence with Urquijo ever after. I met Mr. Carlisle at the house of Mr. P. Knight, in Soho Square) the surgeon, who told me the story, happened to pass by when he was dragged out in a state of insensibility, and superintended his recovery by the means recommended by the Humane Society. When our Secretary of State called on him, he made a point

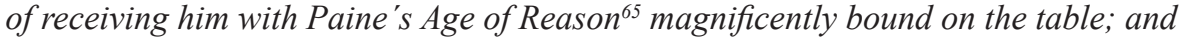
Lord Grenville has more than once accounted to me for the low opinion he entertains of Spanish politicians, by the circumstance of Urquijo, the wildest and most incapable man he ever transacted business with, being elevated to the station of First Minister. Recommended to the Queen by his personal beauty alone, he is said to have slighted her advances, a throughout his administration to have preferred, even to ostentation, the Princess Branciforte, sister of the Prince of Peace his most dangerous rival. Intent on various reforms, - such as the suppression of Inquisition and of several monastic institutions, the appointment of a patriarch, and the transference of all Spanish causes from the Dataria at Rome to national tribunals, - he began by removing from office and from Court those men whose talents, gravity, and principles, by shedding some lustre on his measures, might have softened the odium to which such during innovations must obviously have been exposed. He seemed to look for support from the foreign ministers exclusively. He was much connected with Valckenaer, the

${ }^{65}$ Thomas Paine fue un escritor británico, publicista de las ideas ilustradas, que apoyó la declaración de independencia americana y defendió los frutos de la Revolución Francesa. La Edad de la Razón (1794) contiene un ataque hacia la religión institucionalizada. Su obra anterior, Los derechos del hombre, era un ataque a las Reflexiones de Burke. 
minister from the Batavian Republick ${ }^{66}$, and Borel, the Saxon envoy ${ }^{67}$. At the instance of the latter, he engaged in a negotiation to effect a marriage between the Prince of Asturias and a princess of Saxony, with whom he expected a considerable dowry [...] The scheme of the Saxon marriages, if it did not contribute in some degree to the downfall of Urquijo, shared the fate of that minister. It was abandoned on his disgrace, and the Saxon minister, after being unjustly accused of purloing minerals from the Museum, and exposed to many other unmanly and ungenerous persecutions, went mad, and died of vexation and chagrin.

Urquijo, from self-sufficiency, was always confident of his own favour at Court, and of the weakness of his adversaries, especially the Prince of the Peace. Though warned even by his sister at the imprudence of such a step, he allowed him to re-appear at the Sitios. A cabal was formed between the formidable favourite, the Nuncio, and the dignified clergy, who dreaded the design of appointing a patriarch and withdrawing all submission to the Datarie at Rome. They alarmed Charles IV with the prospect of a schism in the Church; and it is said that a remonstrance against the plans of the reforming minister, and a laboured statement of the consequences to be apprehended, were presented by the Nuncio to the King himself at St. Ildefonso, when Urquijo had proceeded to Madrid. Whether the Queen was a party to this intrigue or not, I don't know. From returning love for the Prince, or from fear, she acquiesced; for it is certain that Urquijo was dismissed, banished, and imprisoned in the citadel of Pampeluna in $1800[\ldots]^{68}$.

${ }^{66}$ Johan Valckenaar -también aparece como Walckenaer- fue un revolucionario, jurista y diplomático holandés que permaneció en España desde 1796 a 1801. Sus manejos, entre los que destacan un papel protagonista en el empréstito firmado con la banca holandesa Croese y el tratado de Java, resultaron controvertidos. Véase ROMERO PEÑA, Aleix: "Antecedentes, trasfondo y consecuencias del tratado de Java (1800)", en Cuadernos del Bicentenario, no 5, 2009, pp. 123-140. Azara diría sobre él que es un instrumento del ministro inglés Pitt que ha venido a España a sembrar su ruina fomentando el contrabando con Mahón y Gibraltar, en manos británicas. V. GIMENO PUYOL, Mª D., op. cit. (nota 27), p. 940.

${ }^{67}$ El barón Philippe de Forell, de convicciones avanzadas y gran aficionado a la geología y mineralogía. Su papel en el periplo americano de Alexander von Humboldt, propiciando un encuentro del científico alemán con Urquijo, resultó fundamental. PUIG-SAMPER, M. Á. y REBOK, S.: Sentir y medir. Alexander von Humboldt en España, Madrid, Doce Calles, 2007.

68 "Mientras tanto la conducta de la Reina se fue haciendo más caprichosa y licenciosa. Urquijo, que tras la ruptura con Inglaterra en 1796 había regresado al país, llegó a ser en virtud de su rango en la Secretaría jefe de oficiales, actuó como Secretario durante la enfermedad del titular, Don Francisco Saavedra. Ese ministro continuó enfermo por un tiempo, y se hizo necesario que alguien familiarizado con los asuntos de la secretaria leyera, de acuerdo con la costumbre, los despachos a Sus Majestades. Para dar a Urquijo el rango requerido a tal honor fue nominalmente designado embajador de la República Bátava, y acudió a la mesa ante la que estaban sentados el Rey y la Reina a leer la correspondencia oficial. Urquijo era joven, guapo y bien formado. Su Majestad, más que aleccionada por los despachos, quedó impresionada por su lector. A despecho de la etiqueta, si no del decoro, ella le ofreció que acercara una silla y le leyera los papeles a la oreja. Tal condescendencia fue el precedente de grandes favores. Poco después fue nombrado Ministro de Asuntos Exteriores. Saavedra y Jovellanos fueron destituidos y desterrados; pero como la exoneración de ambos, especialmente la de Saavedra, fue precedida de una enfermedad muchos de los que detestaban a la Reina y algunos de los odiaban al Príncipe de la Paz, atribuyeron sus enfermedades a un veneno, administrado según la versión del primero con el objetivo de facilitar la promoción de Urquijo y, de acuerdo también con las asimismo improbables conjeturas del segundo, para vengar la ingratitud y eludir la enemistad de 
En ambas narraciones Mariano Luis de Urquijo encarna la paradoja española entre el ideario jacobino - "our brave Sans-culotte" según la jocosa expresión de Blanco White que da título al presente trabajo- y el hombre cortesano del Antiguo Régimen. Estas contradicciones, perfectamente evidenciables en un personaje de las

estos dos ministros hacia el descartado favorito. La administración de Urquijo, a quien nunca conocí personalmente, duró más tiempo que el que podría haber parecido a cualquier hombre razonable que supiese de las extrañas historias que se contaban sobre él. Él fue ignorante, precipitado y presuntuoso hasta el extremo. Aunque bajo su gobierno silenció toda opinión contraria, ya fuese proveniente tanto del pueblo como de las instituciones, se propuso, sin embargo, ilustrar a los individuos hasta el punto de pasar por alto las precauciones más necesarias para la ejecución de sus arduas tareas. Fue tan fanáticamente hostil a la Iglesia de Roma que cuando era encargado de negocios en Londres, al escuchar que el general Bonaparte, por la paz de Tolentino y la mediación del embajador español Azara, había respetado el gobierno papal corrió como un poseso desde su residencia hasta la carretera de Uxbridge, a más de una milla, y se arrojó desesperado por el puente. Mr. Carlisle (nota: ésta es una extraña, casi increíble historia, pero doy mi palabra sobre ella. Se la he hecho repetir a Mr. Carlisle más de una vez y él menciona muchos detalles sobre el suceso, asegurándome además que había mantenido una amistad íntima y correspondencia con Urquijo desde entonces. Yo conocí a Mr. Carlisle en la casa de Mr. P. Knight, en Soho Square), el cirujano que me contó la historia, coincidió a pasar por allí cuando Urquijo fue sacado de las aguas en estado de inconsciencia, y supervisó su recuperación mediante los medios recomendados por la Sociedad Humana. Cuando nuestro Secretario de Estado le visitó, él le recibió intencionadamente con un ejemplar magníficamente bordado de Age of Reason de Paine colocado sobre la mesa; y Lord Grenville me ha contado más de una vez la mala opinión que le merecen los políticos españoles a causa de que Urquijo, el más loco e incapaz hombre con quien haya llevado asuntos, sea elevado al puesto de Primer Ministro. Recomendado por la Reina exclusivamente en razón de su belleza personal, se comenta que desairó sus requerimientos durante todo su gobierno por haber preferido, incluso haciendo ostentación, a la Princesa de Branciforte, hermana del Príncipe de la Paz, su más peligroso rival. Resuelto a realizar varias reformas -como la supresión de la Inquisición y de varias instituciones monásticas, el nombramiento de obispos y la transferencia de todas las causas españolas de la Dataría de Roma a tribunales nacionales-, comenzó eliminando del ministerio y de la Corte a todos aquellos hombres cuyos talentos, seriedad y principios, emitiendo algún lustre a las medidas podían haber atenuado el encono al que se expusieron tales innovaciones en dicha época. Pareció buscar apoyos de forma exclusiva en los embajadores extranjeros. Estuvo muy relacionado con Valckenaer, ministro de la República Bátava, y el enviado sajón Borel. A instancias del último se comprometió en una negocación para acordar el matrimonio entre el Príncipe de Asturias y la Princesa de Sajonia, de quien esperaba una considerable dote [...] El plan de los casamientos sajones, si bien no contribuyó de ningún modo a la caída de Urquijo, compartió el destino del ministro Urquijo. El proyecto fue abandonado en la desgracia de éste, y el ministro sajón, después de ser injustamente acusado de hurto de minerales del Museo y expuesto a muchas otras persecuciones injustas y mezquinas, se volvió loco y murió de vejación y disgusto. Urquijo, con una enorme seguridad en sí mismo, estuvo siempre confiado de su favor en la Corte, así como en la debilidad de sus adversarios, especialmente del Príncipe de la Paz. Aunque estaba advertido por la hermana de aquél de la imprudencia de ese paso, le permitió reaparecer en los Sitios. Se formó una cábala compuesta por el formidable favorito, el Nuncio y el alto clero, que temía el propósito de nombramiento de obispos y el fin de toda sumisión a la Dataría de Roma. Alarmaron a Carlos IV con la perspectiva de un cisma en la Iglesia; y se dice que una reconvención contra los planes del ministro reformista y una elaborado extracto de las consecuencias que se recelaban, fue presentada por el Nuncio en mano al Rey en San Ildefonso, cuando Urquijo había marchado a Madrid. Si la Reina tuvo parte o no en la intriga, no lo sé. Ya fuese porque renacía su amor por el Príncipe de la Paz, o su miedo, ella consintió; lo que hay de cierto es que Urquijo fue destituido, desterrado y encarcelado en la ciudadela de Pamplona en 1800 [...]". Cfr. lord HOLLAND: Foreing reminiscences, op. cit. (nota 59), pp. 98-105. 
coordenadas temporales de Urquijo ${ }^{69}$, no llegaron al grotesco extremo que reflejan Blanco White y Lord Holland. Los dos autores insisten en señalar que la Ilustración de Urquijo fue superficial y que, en el fondo, sólo escondía una inquina fanática contra la Iglesia católica. De ahí que sólo se detengan en su decreto sobre dispensas matrimoniales, que pretende ser entendido como producto de ese odio. Se trata de una visión simplista que se refuerza con la narración de episodios difícilmente creíbles ${ }^{70}$, sobre los que además contamos con la existencia de testimonios muy distintos. Sirva como ejemplo la narración de García de León y Pizarro sobre el nombramiento de Urquijo para comprobar la disparidad de las versiones, apareciendo nuestro personaje, en este caso, revestido en unos valores radicalmente contrarios a los representados por Blanco White y lord Holland.

Entonces llegaron unos despachos interesantísimos de París, y he aquí los apuros. Los reyes determinan ver si Urquijo tenía capacidad para el despacho; lo llaman, y él, aprovechándose diestramente, no sólo dio cuenta y comentó dichos despachos sino que presentó el cuadro de todas las negociaciones pendientes con Francia, con la facilidad común a los que entienden y han trabajado en estas materias, y, además, con la serenidad y petulancia natural a su carácter.

Urgía dar vado a los negocios, y hecho este examen, los reyes se decidieron a autorizarle para que él los despachase. Le indican la idea, y él, nada lerdo, aprovecha la ocasión y hace ver las dificultades que el caso presenta por la solemnidad que exigen los negocios diplomáticos y la condecoración que requiere el que los despacha. Aplicado así de improviso este estímulo, hizo entrever modestamente una salida; la reina urgió a que la explicase; él la hizo entrever con una timidez aparente; le mandaron entonces que bajase a la Secretaría y trabajase el decreto para el día siguiente, franqueándole el que Saavedra había dejado la víspera para su destrucción. Pero él, que conocía muy bien cuán escurridiza es la ocasión en las cortes, manifestó que la cosa urgía, y que los de la carrera no necesitaban de preparación, y si SS. MM. se lo permitían, allí, a su vista, extendería el decreto. Este golpe era decisivo; lo extiende, en efecto, en términos de quedar él habilitado para el despacho y también para la firma precedida por la expresión "por indisposición del señor Saavedra"; y al mismo tiempo nombrándose embajador en la corte de Holanda, con lo cual a la vez que se caracterizaba para facilitar la conservación del Ministerio, se aseguraba una salida para todo percance". ${ }^{71}$

En conclusión, la imagen que ofrecen las narraciones de Blanco White y lord Holland se encuentra lastrada por la utilización de fuentes escasas y parciales. La doble circunstancia de Urquijo fuera ministro de Estado de la monarquía josefina-donde, frente a sus contradicciones anteriores, defendió una Constitución inequívocamente

\footnotetext{
${ }^{69}$ Véase FRANCO RUBIO, G. y LÓPEZ-CORDÓN, Ma V., op. cit. (nota 1), pp. 1260-1261.

${ }^{70}$ Sobre la historia del presunto suicidio de Urquijo Holland añade en una nota a pie de página que él la certifica, añadiendo que la conoce de boca del mismo salvador de Urquijo, mr. Carlisle, a quien conoció en casa de Mr. P. Knight. Cfr. lord HOLLAND: Foreing reminiscences, op. cit. (nota 59), p. 101.

${ }^{71}$ Cfr. GARCÍA de LEÓN y PIZARRO, J.: op. cit. (nota 57), pp. 73-74.
} 
liberal ${ }^{72}$ - y que, por otra parte, muriese a los pocos años de iniciar su exilio sin dejar para la posteridad un escrito donde defendiera su conducta afrancesada o resaltara su pensamiento político ${ }^{73}$, tampoco posibilitó un retrato más positivo. La descripción resulta en los relatos de Blanco y lord Holland forzada y caricaturesca, muy a propósito para demostrar el estado de decadencia, postración y corrupción moral con que pintaron el reinado de Carlos IV. Unas narraciones que, aunque lastradas por errores y prejuicios, son necesarias revisar para estudiar la biografía de Urquijo o, cuando menos, su difusión durante el siglo XIX.

${ }^{72}$ Entre los artículos que propuso que figurasen en la Constitución se encuentra la abolición de los derechos feudales, la abolición de los oficios enajenados, la inamovilidad de los jueces, la separación entre las justicias civil y eclesiástica, instancia única ante los tribunales de provincia, etc. V. SANZ CID, C., La Constitución de Bayona, Madrid, Reus, 1922, Apéndice III, pp. 468-475. La introducción de estas novedades se oponía, manifiestamente, al ideario constitucional de lord Holland.

${ }^{73}$ Quizás deberían tenerse en cuenta las Memorias para la historia de la revolución española (París, 1814), escritas por Juan Nellerto, seudónimo de Juan Antonio Llorente. Contienen tantas referencias y documentos sobre Urquijo que hacen pensar que éste apadrinó el texto o, por lo menos, aportó materiales. V. JURETSCHKE, H., Los afrancesados en la Guerra de la Independencia. Su génesis, desarrollo y consecuencias históricas, Madrid, Rialp, 1962, pp. 208-209. 